\title{
A TWO YEAR OBSERVATION ON TREND OF PRIMARY GLOMERULONEPHRITIS IN A TERTIARY CARE HOSPITAL OF BANGLADESH
}

\author{
TABASSUM SAMAD ${ }^{1}$, WASIM MD MOHOSIN UL HAQUE ${ }^{2}$, MUHAMMAD ABDUR RAHIM ${ }^{3}$, MEHRUBA ALAM \\ ANANNA $^{3}$, SARWAR IQBAL ${ }^{4}$
}

\begin{abstract}
Aim: Glomerulonephritis remains the most probable underlying cause of end stage renal disease of uncertain aetiology in many developing countries, including Bangladesh. The pattern of glomerular disease varies widely from country to country. In Bangladesh, the incidence and histological pattern of glomerulonephritis is inadequately described. We performed a study, aiming to determine pattern of primary glomerulonephritis in a tertiary care hospital of our country.

Material \& Methods: It was a cross-sectional hospital based prospective study conducted at BIRDEM general hospital starting from from July 2013 to June 2015. It included all patients with primary glomerulonephritis and who underwent native kidney biopsy.

Result: Total 67 biopsy were performed and among them primary glomerulonephritis was 42 . Female and male ratio was 1.3:1 and mean age was 42.73 \pm 14 (14-75) years. Indications of biopsy were proteinuria (>1gm/day) and unexplained acute kidney injury. The commonest histopathological pattern in primary glomerulonephritis was membranoproliferative glomerulonephritis 33.33\% (14/ 42) followed by mesangial proliferative glomerulonephritis 30.95\% (13/42). Only three (7\%) patient required blood transfusion for post biopsy bleeding. No one required nephrectomy.

Conclusion: In conclusion, mesangial proliferative and membranoproliferative glomerulonephritis are the two most common causes of primary glomerulonephritis. Nephrotic range proteinuria was the main indication of biopsy. Post biopsy complication was negligible. Creation of a national renal registry is essential for obtaining more specific epidemiological data.
\end{abstract}

Key Words: Glomerulonephritis, Histopathology, DM

Received: 03 March 2016

Accepted: 09 June 2016

\section{Introduction}

Glomerular disease is a common cause of end stage kidney disease (ESKD) in both developing and developed countries. The pattern of glomerulonephritis (GN) varies widely from country to country, reflecting the possible effects of socio- economic, genetic and environmental factors. ${ }^{1}$ The disease spectrum has also been changing over the last few decades. ${ }^{1}$ IgA nephropathy is the common primary glomerular disease from East Asia, as well as in white Europeans and American. ${ }^{2-5}$ In contrast, focal segmental glomerulosclerosis (FSGS) is the most common glomerular disease among AfricanAmericans, South Americans and Middle East. ${ }^{6,7}$
Currently,we do not have a central biopsy registry in Bangladesh. Statistics on the prevalence of renal disease in Bangladesh are limited. In light of the paucity of published data from our country, this study was done to describe the histopathological pattern of primary glomerular disease in a tertiary care hospital in Bangladesh.

\section{Material and Methods}

This was a cross- sectional hospital based observational study. It included all patients with primary GN and who underwent native kidney biopsy that were performed in "Bangladesh Institute of Research and Rehabilitation in Diabetes, Endocrine

1. Registrar, Nephrology, BIRDEM General Hospital, Shahbag, Dhaka 1000,Bangladesh

2. Associate Professor, Nephrology, BIRDEM General Hospital, Shahbag, Dhaka 1000,Bangladesh

3. Assistant Professor, Nephrology, BIRDEM General Hospital, Shahbag, Dhaka 1000,Bangladesh

4. Assistant Professor, Nephrology BIRDEM General Hospital, Shahbag, Dhaka 1000,Bangladesh

5. Associate Professor, Nephrology, BIRDEM General Hospital, Shahbag, Dhaka 1000,Bangladesh

Address of Correspondence: Dr. Tabassum Samad, FCPS(medicine), Registrar, Nephrology, Ibrahim Medical College and BIRDEM general Hospital, Shahbag, Dhaka 1000,Bangladesh. Mobile:+8801711282434, Email: samadtabassum@yahoo.com 
and Metabolic Disorders" (BIRDEM) General Hospital over a period of two years starting from July 2013, were analyzed. Total 67 biopsy were performed and among them primary GN was 42 .

\section{Variables}

We recorded the demographics of cases, co morbidities, fundoscopic examination findings, indication for renal biopsy, histopathological diagnosis, post biopsy complication and relevant laboratory investigations.

\section{Indication of biopsy}

Indications of biopsy were proteinuria > $1 \mathrm{gm} /$ day with or without glomerular hematuria and unexplained acute kidney injury. Diabetic patients were biopsied if they had unexplained proteinuria, proteinuria $6 \mathrm{gm}$ or more in 24 hours or any features suggestive of glomerulonephritis.

\section{Biopsy technique}

Kidney biopsy was performed for all selected patients using $16 \mathrm{G}$ automated biopsy needle. Atleast two cores of tissue were taken from each patient for light microscopy and direct immunoflurescence (DIF) techniques

\section{Histopathology technique}

For light microscopy, samples were fixed in $10 \%$ formalin solution and sections were stained with hematoxylin and eosin (H\&E) and periodic acid Schiff (PAS).The other sample was preserved in normal saline for DIF study. Immunofluroscence microscopy panel included staining for IgA, IgG, IgM, C3 and C1q. Electron microscopy was not available for diagnostic purpose in our country.

\section{Representation of the histopathological reports}

Minimal change disease (MCD), focal segmental glomerulosclerosis (FSGS), membranous nephropathy $(\mathrm{MN})$, mesangialproliferative glomerulonephritis (MesPGN), membranoproliferative/ mesangiocapillary glomerulonephritis (MPGN/MCGN),IgM nephropathy, IgA nephropathy, focal segmental proliferative GN (FSPGN), diffuse proliferative GN (DPGN), crescentic GN(Cres GN), poststreptococcal GN (PSGN), pauciimmune GN were included in PGN. ${ }^{8}$

Cases were again classified into a) proliferative GN which included MesPGN, MPGN, IgM nephropathy,Ig A nephropathy, FSPGN, DPGN, CresGN, PSGN, pauci-immune GN b) non- proliferative GN which include MCD,MN,FSGS.

\section{Data handling}

All available data were noted into a specially designed questionnaire and were analyzed using Statistical Package for Social Sciences (SPSS) version 20 computer software. Results were expressed as median or mean \pm standard deviation for continuous data and as frequencies with percentages for categorical data.

\section{Results}

Primary GN was found in total 62.68\% (42/67) cases. Female and male ratio was $1.3: 1$ and mean age was $42.73 \pm 14(14-75)$ years. $50 \%$ of the study population had diabetes mellitus.

Indications of biopsy were nephrotic range proteinuria $(17 / 42,40.47 \%)$ including diabetic patients irrespective of the status of retinopathy if 24 hour urinary protein excretion is $6 \mathrm{gm}$ or more, nonnephrotic range proteinuria with / without hematuria $(14 / 42,33.33 \%)$ including diabetic patients but with normal fundus and unexplained AKI (11/42,26\%).

The commonest histopathological pattern in PGN was MPGN 33.33\% (14/42) followed by MesPGN 30.95\% (13/42) (Fig 1). These cases were also classied as proliferative (35) and non proliferative GN (7) (Table I).No distinct pathological pattern were found in any age group (Table II) though most of the MPGN and MesPGN were in between 31-60 age range.

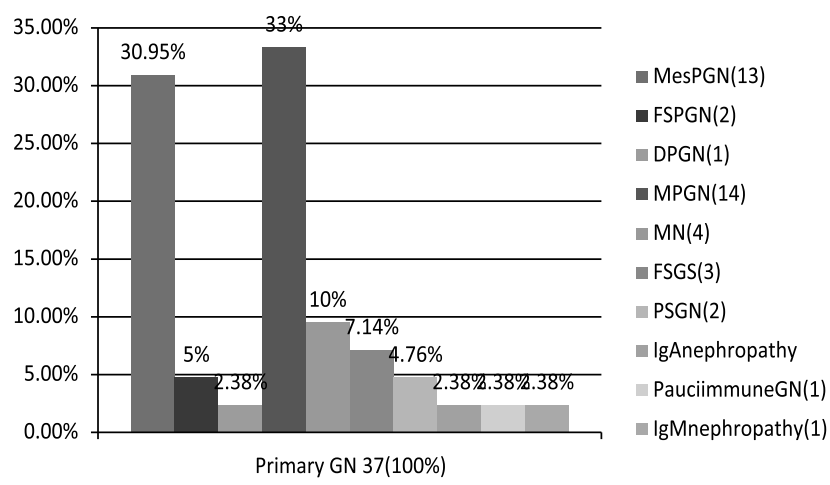

Fig 1: Histological pattern of primary glomerulonephritis

(MPGN= Membranoproliferative GN, MesPGN= Mesangioproliferative GN, DPGN \& FSPGN=Diffuse $\&$ focal segmental proliferative $\mathrm{GN}, \mathrm{MN}=$ Membranous nephropathy, FSGS=Focal segmental nephropathy, PSGN=PoststreptococcalGN)

Table I

Proliferative and non proliferative classification of GN

\begin{tabular}{lll}
\hline & $\begin{array}{l}\text { Proliferative GN } \\
(\mathrm{n}=35)\end{array}$ & $\begin{array}{l}\text { Non- proliferative } \\
\text { GN }(\mathrm{n}=7)\end{array}$ \\
\hline Primary GN & MesPGN (13) & .MN(4) \\
& FSPGN(2) & FSGS(3) \\
& DiffusePGN(1) & \\
& MPGN(14) & \\
& IgM nephropathy(1) \\
& IgA nephropathy(1) \\
& PauciimmuneGN(1) \\
& PSGN(2) & \\
\hline
\end{tabular}

(MesPGN:Mesangial proliferative GN,MPGN: MembranoproliferativeGN, FSPGN:Focal segmental proliferative GN,DPGN: Diffuse proliferative GN, MN:Membranousnephropathy,FSGS:Focal segmental GN,PSGN:Post streptococcalGN) 
Table II

Pathological pattern of PGN in different age group (n=42)

\begin{tabular}{lccccccc}
\hline $\begin{array}{l}\text { Diagnosis } \\
\text { (no of cases) }\end{array}$ & $\begin{array}{c}10-20 \\
\text { years } \\
(\mathrm{n}=4)\end{array}$ & $\begin{array}{c}21-30 \\
\text { years } \\
(\mathrm{n}=4)\end{array}$ & $\begin{array}{c}31-40 \\
\text { years } \\
(\mathrm{n}=13)\end{array}$ & $\begin{array}{c}41-50 \\
\text { years } \\
(\mathrm{n}=8)\end{array}$ & $\begin{array}{c}51-60 \\
\text { years } \\
(\mathrm{n}=8)\end{array}$ & $\begin{array}{c}61-70 \\
\text { years } \\
(\mathrm{n}=3)\end{array}$ & $\begin{array}{c}71-80 \\
\text { years } \\
(\mathrm{n}=2)\end{array}$ \\
\hline MesPGN(13) & 2 & 0 & 3 & 3 & 2 & 1 & 2 \\
MPGN(14) & 0 & 2 & 3 & 3 & 5 & 1 & 0 \\
FSPGN(2) & 1 & 0 & 0 & 0 & 0 & 1 & 0 \\
DPGN(1) & 0 & 0 & 1 & 0 & 0 & 0 & 0 \\
MN(4) & 0 & 1 & 3 & 0 & 0 & 0 & 0 \\
FSGS(3) & 0 & 1 & 1 & 1 & 0 & 0 & 0 \\
IgMnephropathy(1) & 0 & 0 & 1 & 0 & 0 & 0 & 0 \\
PauciimmuneGN(1) & 0 & 0 & 0 & 1 & 0 & 0 & 0 \\
PSGN(2)IgMnephropathy(1) & 10 & 00 & 01 & 00 & 10 & 00 & 00 \\
\hline
\end{tabular}

(MesPGN:Mesangial proliferative GN,MPGN: MembranoproliferativeGN, FSPGN:Focal segmental proliferative GN,DPGN: Diffuse proliferative GN, MN:Membranousnephropathy,FSGS:Focal segmental GN,PSGN:Post streptococcalGN)

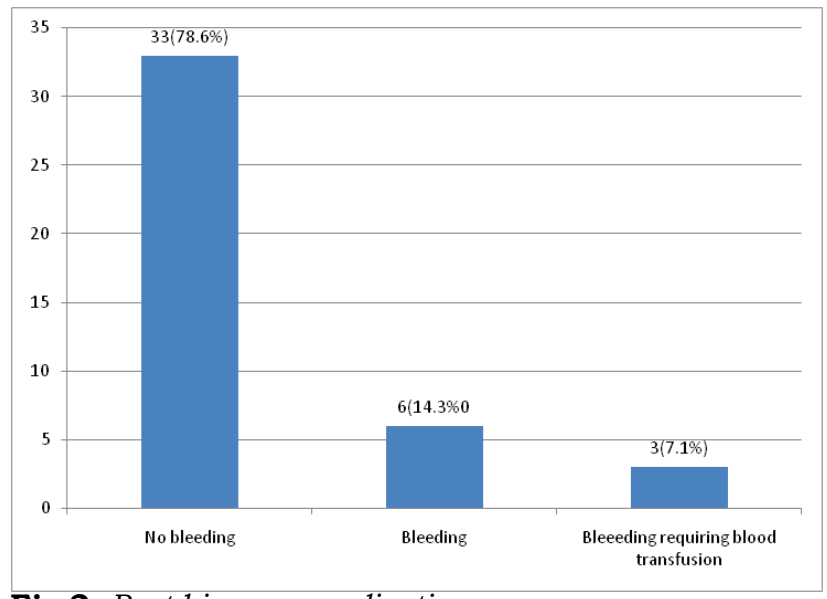

Fig 2: Post biopsy complication

The commonest cause of proteinuria (9/42,21\%) and unexplained acute kidney injury $(5 / 42,12 \%)$ was MPGN .Only three (7\%) patient required blood transfusion for post biopsy bleeding(Table-III). No one required nephrectomy.

\section{Discussion}

The age range of our cases was 14-75 years with a slight female predominance (1.3:1). Habib M A from Bangladesh also found female predominance although most of the studies depict male predominance. ${ }^{9,10-12}$

There was no distinct pathological pattern observed in any age group in our study. Mundi I et al found most of the cases were in 21-40 age range and distinct pattern of PGN was found in different age ranges. 13
Proliferative glomerular disease is the most prominent renal disease in our study as well as in all recent studies. ${ }^{2,14-22}$

In the current study MPGN is the commonest primary GN seen. It is the second most common GN reported by Ahmed et al(11.50\%) and third most common cause $(13 \%)$ of primary GN in Saudi Arabia . 10,23 MesPGN is the second common GN found in current study but in other studies from Bangladesh MesPGN was found to be the commonest primary and proliferative GN. ${ }^{9,15,24}$.

A study on global evolutionary trend of GN done in Singapore for three decades stated that in the $1^{\text {st }}$ decade most Asians countries had MPGN and MesPGN as the most common form of primary GN and still it is prevalent in some Asians countries like China, Japan and Thailand ${ }^{1}$.Apart from geographical,genetic and socioeconomic factor, one factor which may influence the pattern of glomerulonephritis in various countries could be the hygiene hypothesis. ${ }^{25}$ The hygiene hypothesis proposes that bacterial and other infections occurring in less developed or developing countries leads to development of some type of human glomerulonephritis, including MPGN and MesPGN . This would be true in Asian countries like China, Indonesia, Malaysia,Thailand and Singapore which have a high prevalence of MesPGN. ${ }^{24,26-29}$ In some countries like Malaysia and Singapore the prevalence of MesPGN is already decreasing in keeping the urbanization and better housing and other amenities 
in these countries. ${ }^{24,28}$ Bangladesh is a rising country in context of urbanization and other field of developments, i.e, this hypothesis can explain the majority of MPGN as well as MesPGN in our study. Chugh KS also found high prevalence of MesPGN in India but Golay $\mathrm{V}$ etal found lower incidence (0.6\%) in a recent study which does not match our findings and we could not explain that. 30,31

Post infectious GN due to streptococcus used to be prevalent in India and this could account for the high incidence of MPGN as MPGN could also result from post infectious GN. ${ }^{32}$ In our study PSGN rate is low $(4.76 \%)$ and MPGN is higher which resembles with that of India and the low incidence of PSGN could be the fact that the average age of our study population was higher than that of PSGN age group.

Our study findings regarding membranous GN $(\mathrm{MN})(10 \%)$ and focal segmental glomerulosclerosis (FSGS) (7.14\%) slightly differs with Rahman et al showing MN (7.34\%) and FSGS (2.8\%) and with Habib MA which showed MN $7.37 \%$ but FSGS was $11.58 \% .{ }^{9,33}$ Mundi $\mathrm{I}$ etal and Mannan $\mathrm{R}$ et al demonstrated FSGS, MN and minimal change disease(MCD) being the commonest form of PGN in India. ${ }^{12,13}$ Data from Singapore and other countries also showed that the prevalence of FSGS and MN have become increased in recent time ${ }^{1}$ This may be related to increasing number of patients with obesity, $\mathrm{DM}$ and smoking habits, a pattern representing the rising affluence in these countries where FSGS represents the changing life style of fast food and unhealthy diets predisposing to disease like obesity and DM. In our study though many of our cases were diabetic but there average body built and life style do not yet match with that of the affluent society. Apart from this FSGS has been found to have a racial predilection. ${ }^{13}$ Meckenzie etel, have suggested that genetic variation may play a role in sporadic FSGS in adult. 34 These hypothesis also fits with our findings of FSGS but the reason of low incidence of MN could not be explained by us.

Other findings with low incidence of IgM nephropathy and pauciimmune GN matches with other studies like in Pakistan where the incidence of IgM nephropathy was $2.47 \%{ }^{12,13,35}$ Most of the studies did not mention IgM nephropathy as a distinct category. ${ }^{12}$

Incidence of IgA nephropathy in our study is only $2.3 \%(1 / 42$. It is the most common form of primary GN in Asia, accounting for upto $30-40 \%$ of all biopsies, for $20 \%$ in Europe and for $10 \%$ in North America but the incidence of IgA nephropathy in our country is much lower (4.67\%-7\%)in comparison with other Asian countries. 9,12,35,36,39 It was also uncommon in studies from this region of world like in India and Pakistan. ${ }^{32,35}$ This may be explained by varying approaches to the use of renal biopsy in patient with mild urinary abnormality like asymptomatic microscopic hematuria irrespective of degree of proteinuria. ${ }^{18}$ In our center cases with micro/ macroscopic hematuria and proteinuria less than 1 gm/L were not indicated for renal biopsy. Thus the paucity of IgA nephropathy is mostly due to the benign presentation of the disease.

We found that nephrotic range proteinuria is the most frequent clinical presentation, accounting for $40.47 \%$ of all cases. This is similar to that reported in many studies around the world, including India, Pakistan and also Bangladesh. 9,17,19,22,32 The underlying eitiology of nephrotic syndrome is variable across the world .In our study the commonest cause of nephrotic range proteinuria is MPGN (26\%), and than MesPGN (17\%). Huq $N$ also reported MesPGN (36.48\%) and MPGN ( $20.27 \%$ ) as the common cause of nephrotic syndrome. ${ }^{38}$ In Korea and other northeast countries like Japan, the most common cause of NS was MCD, followed by MN and IgA nephropathy. ${ }^{14} \mathrm{Membranous}$ nephropathy (10.81\%) was not much common in Bangladesh as we reported. We did not get any minimal change disease. ${ }^{38}$ Several studies have shown a decline in the relative frequency of MCD. ${ }^{32}$ China also reported a very low incidence of MCD. 22

The overall frequency of important complications after renal biopsy varied from $5 \%$ to $13 \%$ in previous reports which mainly included hematuria. ${ }^{36,37}$ One death was also been reported from renal biopsy. ${ }^{37}$ In our study only three patient required post biopsy blood transfusion for bleeding. This may be minimized in future by performing biopsy under USG guidance.

\section{Limitation}

A large number of study subjects from multi-centre and availability of electron microscope could make our study more representative.

\section{Conclusion}

To conclude, from the study and data analyzed, the prevalence of PGN is different all over the world due to various factors. PGN related to infection i.e MesPGN and MPGN, is more common in our country whereas IgA nephropathy, FSGS is not very prevalent. Nephrotic syndrome is most commonly encountered indication for biopsy and the study depect renal biopsy as a relatively safe procedure in expert hand. It has also been realized that it is essential and necessary to maintain a central biopsy registry with an increased participation of many more nephrology center of 
Bangladesh to obtain accurate knowledge about incidence, spectrum and distribution of glomerulonephritis in our country.

\section{References:}

1. Woo KT, Chan CM, Chin YM, Choong HL, Tan HK, Foo $\mathrm{M}$ et al. Global evolutionary trend of the prevalence of primary glomeruloneph itis over the past three decades. Nephron Clin Pract 2010;116:c337-46

2. Chang JH, Kim DK, Kim W. Changing prevalence of glomerular diseases in Korean adults: A review of 20 years of experience. Nephrol Dial Transplant. 2009;24:2406-10.

3. Utsonomiya Y, Koda T, Kado T, Okada S, Hayashi A, Kanzaki S, etal.. Incidence of pediatric IgA nephropathy Pediatr Nephrol 2003;18:511-5

4. Gesualdo L, Di Palma AM, Morrone LF, Stripolli GF, Schena FP. The Italian experience of the national registry of renal biopsies. Kidney Int 2004;66:890-4

5. Hanko JB, Mullan RN, O'Rourke DM, McNamee PT, Maxwell AP,Courtney AE. The changing pattern of adult primary glomerular disease.Nephrol Dial Transplant 2009;24:3050-4

6. Barden GL, Mulhern JG, O'Shea MH, Nash SV, Ucci AA $\mathrm{Jr}$, Germain $\mathrm{MJ}$. Changing incidence of glomerular disease in adults. Am J Kidney Dis 2000; 35: $878-83$

7. Mitwalli AH, Al Wakeel J, Abu-Aisha H, Alma A,Al Sohaibani M, Tarif N, et al. Prevalence of glomerular disease:King Khalid University Hospital, Saudi Arabia.Saudi J Kidney Dis Transpl.2000;11:442-8

8. Patrick H, Nachman J, Jennete C, Falk RJ. Primary glomerulonephritis.In:Taal MW, Chertow GM,Marsdon PA,Skorecki K,Yen ASL,eds .Brener \&Rectors The Kidney, $9^{\text {th }}$ edition.Philadelphia,Elsevier;2012;1:1100-1191

9. Habib MA,Badruddoza SM.Pattern of glomerular disease among adults in Rajshahi,the northern region of Bangladesh. Saudi J kidney Dis Transpl 2012;23(4):876-880

10. Mannan R, Bhasin TS, Singh PA, Misra V, Manjari M.The pattern of glomerulonephritis in the North Indian Gangetic Plain- a 13 year epidemiological study.Journal of clinical and diagnostic research.2012;6(5):855-858

11. Das U,Dakshinamurty KV,Prayaga A. Pattern of biopsy proven renal disease in asingle center of south India: 19 years experience. Indian $\mathrm{J}$ Nephrol.2011;21(4):250-256

12. Ahmed P I, Zaman S U, Jahan F, Gupto R D, Chowdhury $\mathrm{M} N$, et al. Pattern of primary glomeruloglomerulonephritis in Dhaka Medical
College Hospital,Bangladesh. Bangladesh J Medicine.2014;25: 42-46

13. Mundi I,D'cruz S, Punia P.S, Kaur R, Sachdev A. Clinicopathological study of glomerular disease in patients with significant proteinuria in North India. Saudi J Kidney Dis Transpl 2014;25(2):443-449

14. Research Group on Progressive Chronic Renal disease. Nationwide and Long-Term Survey of Primary Glomerulonephritis in Japan as Observed in 1,850 Biopsied Cases. Nephron. 1999;82:20513.

15. Hurtado A, Johnson RJ: Hygiene hypothesis and prevalence of glomerulonephritis .Kidney Int 2005;68:s62-7

16. Chen $\mathrm{H}$, Tang $Z$, Zeng $\mathrm{C}$,et al. Pathological demography of native patients in a nephrology center in China.Chinese Med J (Engl)2003;116:1377-81

17. Sidabutar RP: Glomerulonephritis in Indonesia.Proc $3^{\text {rd }}$ Asian Pacific congress on Nephrology,Singapore, 1986,pp 282-91

18. Looi Lm: The pattern of renal disease in Malaysia. Malayas J Pathol 1994;16:19-21

19. Parichatikanond P, Chawanasuntorapoj R,Shayakul C,et al. An a nalysis of 3555 cases of renal biopsy in Thailand.J Med Assoc Thai 2006;89(suppl 2): S106-11

20. Chugh KS. Renal diaeasa in India.Am J Kidney Dis 1998;31:17-9

21. Golay V, Trivedi M, Abraham A, Roychowdhury A, Pandey R. The spectrum of glomerular disease in a single center: A clinicapathologial co relation. Indian J Nephrol 2013;23(3)::168-75

22. Nawaz Z, Mushtaq F, Mousa D, Rehman E, Sulaiman $\mathrm{M}$, Aslam $\mathrm{N}$ et al.Patternof glomerular disease in in the Saudi population: A single center ,five year retrospective study. Saudi J Kidney Dis Transpl 2013: 24(6): 1265-70

23. Rahman MS. A study on histomorphological patterns of glomerulonephritis in nephritic syndrome. (Thesis). Dhaka,Bangladesh:BSMMU;2006

24. Balakrishnan N, John Jt, Korula A, et al: Spectrum of biopsy proven renal disease and changing trends at a tertiary care centre 1990-2001. Indian J nephrol 2003;13:29-35

25. Mitwali Ah: Glomerulonephritis in Saudi Arabia: a review.SaudI J Kidney dis Transpl 2000;11: 56776.

26. NarasimhanB, Chacko B, John GT,Korula A, Kirubakaran MG,Jacob CK.Characterization of kidney lesion $\mathrm{s}$ in India $\mathrm{n}$ adults: Towards a renal biopsy registry.Nephrol 2006;19:205

27. Rahman $\mathrm{T}$, Islam N, Rashid HU, Rahman M. Morphological pattern of glomerular disease 
presentation with nephritic syndrome- an experience based on light microscopy of needle biopsy. Bangladesh Renal J 1984;3:1-5

28. McKenzie LM, Hendrickson SL, Briggs Wa, etal: NPHS2 variation insporadic focal segmental glomerulosclerosis. J Am Soc Nephrol 2007;18: 2987-95

29. Mubarak M, Kazi JL, Naqvi R, Ahmed E,Akhter F, Naqvi SA, etal. Pattern of renal disease observed in native renal biopsies in adult in a single center in Pakistan. Nephrology 2011;16:87-92

30. Falk RJ, Jennette C, Nachman PH.Primary glomerular disease.In: Brennwr BM,ed.The kidney, $7^{\text {th }}$ ed.Philadelphia:W.B Saunders Company; 2004. p. 1293-354

31. Rashid HU, Sharmin S, Khanam A, Islam A, Ahmed J. Clinical presentation, histological diagnosis and management of primary glomerulonephritis in Bangladeshi adult population. Bangladesh Renal $\mathrm{J}$ 2003;22:35-38
32. Gesualdo L, Maria A, Francesco L. The Italian experience of the national registry of renal biopsies. Kidney Int. 2004;66:890-4

33. Rychlik1 I, Ova EJ, Tesa V. The Czech registry of renal biopsies.Occurrence of renal diseases in the years 1994-2000. Nephrol Dial Transplant. 2004;19:3040-9.

34. Lei-shi li, Zhi-hongliu Epidemiologic data of renal diseases from a single unit in China: Analysis based on 13,519 renal biopsies. Kidney Int. 2004;66:9203 .

35. In Joon Choi, HyeonJooJeong, Dae Suk Han. An Analysis of 4,514 Cases of Renal Biopsy in Korea. Yonsei Med J. 2001;42:247-5

36. Mendelssohn DC, Cole EH, Outcomes of percutaneous kidney biopsy, including those of solitary native kidneys.Am $J$ Kidney Dis 1995;26:580-5

37. Whittier WL, Korbet SM. Timing of complication in percutaneous renal biopsy. J AM Soc Nephrol 2004; 15:142-7

38. Huq N, H Khatun,SA Jinnah. Morphological Pattern of glomerular disease in adult nephritic syndrome.Mymensing Med J 2011;20(4):652-7. 